\title{
OPINIÃO
}

\section{Sugestões para o aperfeiçoamento do regime de metas de inflação no Brasil}

José Luis Oreiro*

\section{Avanço da Governança da política monetária}

O regime de metas de inflação foi um avanço institucional importante na condução da política monetária no Brasil. No primeiro mandato do presidente Fernando Henrique Cardoso prevaleceu um regime de câmbio semi-fixo (crawling-peg) que manteve a taxa de câmbio artificialmente valorizada no período 1995-1998. Esse arcabouço de política monetária, embora bem sucedido no que se refere à manutenção de níveis baixos de inflação, levou a um desequilíbrio externo de grandes proporções o qual foi, em larga medida, responsável pela manutenção da taxa real de juros em torno de $25 \%$ a.a. Nesse período o país acumulou mais de US\$ 170 bilhões de déficit em conta corrente, os quais foram financiados com capitais especulativos de curto-prazo e aumento do endividamento externo. A fragilidade externa da economia brasileira, somada as sucessivas crises externas (México, Sudeste Asiático e Rússia) levou ao abandono do regime de câmbio fixo em janeiro de 1999 e a adoção do regime de metas de inflação, em meados do mesmo ano, com o intuito de se produzir uma nova âncora para as expectativas de inflação. A desvalorização da taxa de câmbio permitiu a progressiva redução dos déficits em conta corrente o que, por sua vez, levou a uma redução significativa da taxa de juros para cerca de $10 \%$ a.a em termos reais já na virada do milênio. Passados os efeitos da "crise do apagão elétrico" em 2001 e do stress com a eleição do Presidente Lula em 2002, vislumbrava-se a retomada do crescimento da economia brasileira a taxas robustas em torno de 5\% a.a, com juros reais em torno de 5\% a.a. e uma taxa de câmbio pró-exportação.

\section{Expectativas frustradas}

No entanto, o cenário que se vislumbrava de retomada de crescimento da economia brasileira não se concretizou. Em meados de 2004, o BCB iniciou um novo ciclo de elevação da taxa de juros básica, o qual só foi interrompido em setembro de 2005. Esse ciclo de elevação foi seguido por uma apreciação contínua da taxa de câmbio e uma redução significativa do crescimento da economia brasileira. Em 2005 a economia cresceu apenas

\footnotetext{
* Professor do Departamento de Economia da Universidade Federal do Paraná e Pesquisador Nível I do CNPq. Endereço eletrônico: joreiro@ufpr.br. Página pessoal: www.joseluisoreiro.ecn.br.
} 
$2,3 \%$ contra um crescimento de quase $5 \%$ em 2004. Essa desaceleração do crescimento ocorreu num cenário externo altamente favorável com um crescimento acelerado da economia mundial, taxas de juros internacionais baixas e preços elevados das commodities. Foi o BCB o responsável pela interrupção prematura do novo ciclo de crescimento que se iniciava no ano de 2004.

\section{O que deu errado?}

A raiz do problema encontra-se na governança da política monetária no Brasil. O regime de metas de inflação no Brasil padece de uma série de problemas que terminam por gerar as condições propícias para a retomada do ciclo de elevação da taxa de juros, mesmo quando uma avaliação comparativa entre os riscos de retomada da inflação e de desaceleração do crescimento não justificaria essa elevação dos juros.

Os problemas da governança da política monetária no Brasil são os seguintes:

\section{i) Estimativas excessivamente conservadoras sobre o crescimento do produto} potencial da economia. A taxa de juros é um instrumento adequado para se combater inflação de demanda, ou seja, aquela inflação que resulta de um crescimento da economia superior ao crescimento da oferta de bens e serviços. Os modelos usados pelo BCB estimam que o crescimento potencial da economia brasileira varia entre 3.5 e $4 \%$ a.a. Dessa forma, quando a economia brasileira ensaia um crescimento superior a esse patamar, o COPOM vislumbra no horizonte uma elevação da inflação e reage ao mesmo por intermédio de uma elevação preventiva da taxa de juros. O problema dos modelos usados pelo BCB é que eles não levam em conta o fato de que o crescimento do produto potencial depende, em larga medida, do crescimento da economia no passado recente. Assim, quando o BCB aumenta a taxa de juros, o crescimento da economia se desacelera e uma série de novos projetos de investimento é interrompida. Assim sendo, a expansão da capacidade produtiva fica comprometida, o que resulta - por falta de expansão da oferta - no surgimento das pressões inflacionárias que o $\mathrm{BCB}$ queria evitar. Modelos que levam em conta a dependência do produto potencial com respeito ao passado recente da economia sinalizam uma taxa de crescimento não-inflacionária para a economia brasileira que varia entre 5 e $8 \%$ ao ano.

ii) Estimativas viesadas para cima das expectativas inflacionárias: As decisões do COPOM sobre o nível da taxa de juros básica se baseiam em expectativas sobre o 
comportamento da inflação futura. O BCB utiliza, entre outras variáveis, as expectativas de inflação produzidas pelos departamentos econômicos das instituições financeiras. O problema com esse procedimento é que as instituições financeiras têm um claro interesse em sobreestimar a inflação futura para, dessa forma, "forçar a mão" do BCB, levando-o a fixar uma taxa de juros mais alta do que o exigido pela conjuntura econômica. Com efeito, se tomarmos a média das previsões diárias da taxa anual de inflação da TOP 5 - ou seja, as instituições cujas previsões mais se aproximam da inflação efetivamente observada - observaremos um fato curioso: em 2005 a inflação esperada foi de 5,81\% contra uma inflação observada de 5,69\%, e em 2006 a inflação esperada foi de 3,9\% contra uma inflação observada de apenas 3,14\%. Nos dois últimos anos, a inflação esperada pelas TOP 5 sobre-estimou a inflação efetivamente incorrida, numa violação clara ao princípio da racionalidade na formação de expectativas! Sinal claro de que existe um viés altista nas expectativas de inflação das instituições consultadas pelo BCB.

iii) Desinflação rápida. Nos últimos 3 anos a inflação brasileira vem se reduzindo a um ritmo bastante acelerado. Em 2004, a taxa de inflação medida pelo IPCA foi de 7,6\%, em 2005 a inflação foi de 5,9\% e em 2006 a inflação foi de 3,14\%. Num espaço de três anos a inflação brasileira caiu em mais de 50\%! A contrapartida dessa desinflação acelerada foi uma brutal apreciação da taxa de câmbio - decorrente da manutenção de juros elevados em termos nominais e reais - e uma desaceleração do crescimento econômico. Se o ritmo de desinflação tivesse sido menor - por exemplo, uma desinflação de $25 \%$ em três anos - o BCB poderia ter reduzido a taxa de juros muito mais rapidamente, o que teria gerado uma apreciação menor da taxa de câmbio, um maior crescimento econômico e, não menos importante, um déficit fiscal mais baixo, o que teria permitido uma queda mais rápida da dívida pública. Não há dúvida que quanto mais baixa a inflação melhor para o país, mas o problema é a velocidade com a qual esse objetivo é atingido. Nos últimos anos a velocidade de queda da inflação talvez tenha sido muito elevada.

\section{O que fazer?}

Em face desse diagnóstico, acreditamos que as seguintes medidas devem ser tomadas no sentido de aperfeiçoar a governança do regime de metas de inflação no Brasil.

i) Maior interação entre o departamento econômico do BCB e as instituições acadêmicas na área de economia. Os centros de pós-graduação em economia no Brasil, 
reunidos em torno da ANPEC (Associação Nacional dos Centros de Pós-Graduação em Economia) alcançaram padrões de excelência a nível internacional em diversos campos da pesquisa econômica. Essa expertise pode e deve ser aproveitada pelo BCB no sentido de aprimorar os modelos de previsão do produto potencial, assim como as expectativas de inflação de forma a eliminar o viés altista das mesmas. Nesse contexto, sugerimos que o BCB e a ANPEC juntem esforços no sentido de elaborar modelos de previsão de produto potencial e de inflação futura que possam subsidiar as decisões do COPOM;

ii) Estabilidade da taxa de inflação em torno de 4 a $4.5 \%$ a.a nos próximos anos. Tendo em vista os resultados já alcançados no que se refere a redução da taxa de inflação, os benefícios oriundos de uma redução da taxa de inflação para um patamar entre 3 a $3.5 \%$ a.a., como sugerido por alguns economistas mais conservadores, não parecem ser maiores do que os custos desse tipo de estratégia. Uma nova rodada de desinflação, nas circunstâncias atuais, iria reduzir o ritmo de queda da taxa de juros básica, contribuindo para o agravamento do já gravíssimo problema cambial que assola a indústria brasileira. Dessa forma, sugerimos que o Conselho Monetário Nacional não sancione nenhuma iniciativa do BCB no sentido de reduzir a taxa de inflação para baixo de $4 \%$ a.a. Nesse contexto, vemos com preocupação a decisão do CMN de estipular, ainda que informalmente, que o centro da meta de inflação para o triênio 2007-2009, definido em 4,5\% a.a., seja, na verdade, o teto da nova banda de variação do IPCA. Dessa forma, o CMN liberou o BCB a perseguir uma meta de inflação no intervalo entre 2.5 e $4.5 \%$ a.a. Tomando uma média entre esses dois valores, a meta central da "meta informal" passa a ser de 3.5\% a.a, ou seja, uma redução de 100 pontos base com respeito a meta de inflação definida para o ano de 2006. Dado o comportamento pregresso do $\mathrm{BCB}$, corremos o risco de assistir, mais uma vez, o BCB a aumentar a taxa de juros num futuro não muito distante com base no argumento de que ele precisa cumprir a nova meta (mais baixa) de inflação. 